\title{
Editorial: How simple can pensions be?
}

This paper has been written in answer to the deceptively simple question 'Why does UK pensions legislation need simplifying?'. Half of the UK workforce are members of occupational pension schemes provided by their employers. Half are not. Those who are not in occupational schemes can take out individual pension arrangements for themselves. Individual pensions are also available to those who are in their employers' schemes, so that they too can provide additional pension benefits for themselves. All those investing in their future through pension schemes, occupational and individual, receive generous tax benefits; where employers help, they do too. Simply put, this is the basis of private pensions in the UK today.

There has never been a law in the UK requiring individuals or employers to establish, or contribute to, private pension schemes. Nevertheless, people in this country have accumulated over $\mathcal{E} 1,100$ bn worth of pensions savings. The UK has more saved towards employees' pensions than the rest of Europe added together. This voluntary pensions savings habit is almost unique in Europe and one of the great success stories of UK social and fiscal legislation in the latter half of the last century.

State pensions are also available to all employees in the UK. The universal State Basic Pension is supplemented for many by the second-tier earnings-related pension, currently known as Serps. The real value of the pensions provided by the State is, however, falling. Our level of state pension support is already among the lowest in Europe. Research among younger people in the UK workforce shows that the gradual withdrawal of the State from universal pension provision is understood and accepted. That is not to say they are happy about it, but the current young in the workforce seem to be as committed to pension saving as the generations immediately preceding them.

This puts the UK, on the face of it, in an enviable position as far as pensions are concerned. We have an established, voluntary pensions savings culture which has evolved over nearly 50 years; we are not passing legislation to promise ourselves pension benefits that future generations will have to pay for, for us. This is difficult, if not impossible, for other countries to replicate. We have done the hard things.

Perversely, the easy things we need to do are the ones we seem to be unable to do. As far as pensions are concerned it seems that all that responsible people who are prepared, and able, to save really require is a simple and safe environment in which to do so. For some reason, this is denied to them.

In reality, the subject of pensions is needlessly complex and over legalistic. Idiosyncrasies, inconsistencies and different laws for different schemes abound; I hope to demonstrate this through this Editorial. It is essential for government to encourage and help people to save for their old age and not to obstruct people from doing this by 
building a complex maze of legislation that serves only to confuse. To this end, simplifying the rules governing pension savings must be the way forward. Legislation for both occupational and individual pension schemes should have only one purpose - to help people save for their old age.

Over the last 20 years or so, pensions have tended to become an exclusive and overly-complex game, so much so that it seems only initiated insiders can now play it. Jargon and convoluted language daily obstruct rather than help ordinary people to save. The very complexity of the language has spawned a new industry, as experts provide 'simple' translations of what legislation and regulations mean. While one applauds the skill of these players and their interpretations, is it really necessary?

Today, in effect, it is left to the market and its priesthood to try and make sense of the laws and regulations that have been passed. Their role has become one of designing ever more complicated products, tailored to suit the environment rather than meeting people's needs. In a way these sophisticates are the only winners in this intricate game.

The losers are:

- those individuals trying to be responsible and save for their old age. Confused by the whole environment, they may make the wrong choices and lose out. This is a misuse of the virtue of providing choice. Choice without understanding is of little use to anyone

- those who find the whole environment so confusing they take the easy path and decide to do nothing

- those employers who are, and have been, prepared to establish occupational pension schemes for their employees, but find that the sheer complexity of running a good scheme begins to outweigh the benefits of doing so.

However, the biggest loser, by far, is the State, namely the rest of us and those who follow us in the future. Unless people can find their way through the pensions maze and save enough for their old age, then in the future they will look more and more to the State for support. This is neither desirable nor sustainable.

The tax reliefs attached to pension savings are important and valuable to individuals and employers. Where tax reliefs are given to encourage and reward pension saving there is a limit set on the amount of tax relief allowed so that the system is not abused by those fortunate enough to be in a position to be able to afford to do so. There are two ways that the tax relief given can be restricted; either the benefits provided can be limited, or the contributions allowable can be limited. In the UK we are lucky enough to have both systems operating at the same time.

As a general rule occupational pension schemes are benefit limited, whereas individual pension arrangements are contribution limited. This means we have, broadly, two separate pension tax regimes in the UK, one for occupational schemes and one for individual schemes. Unfortunately though, it is not quite that simple. There are in fact many 'sub-regimes' within the two main tax regimes and the reality is that both regimes are now comprised of a mish-mash of both benefit and contribution limits.

There are two basic forms of pension arrangement; defined-benefit schemes and defined-contribution schemes. These are sometimes referred to respectively as final-salary schemes and money-purchase schemes. Defined-benefit schemes are exclusively occupational schemes, 
whereas individual pension schemes are exclusively defined-contribution based. However, it is becoming increasingly common for employers to provide defined-contribution schemes for their employees and until recently this has been done with the overall defined-benefit limits still applying (to prevent over investment on a money-purchase basis). But since April 2001, employers have gained the right to provide defined-contribution schemes outside of the defined-benefit limitations, though still within the existing Personal Pension contribution limitations. This is a recently introduced complexity which allows schemes to be approved under one set of tax rules, while the pension benefits of the members are governed by another.

The essential differences between defined-benefit occupational schemes and defined-contribution occupational schemes are the form in which pension benefits emerge and the question of who takes the risks related to investment and to annuity purchase. In a defined-benefit scheme the benefits provided on leaving service, transfer, early retirement, normal retirement, late retirement or death are prescribed according to certain formulae and the employer is responsible for meeting the cost of such benefits. The advantage to employees is that (in theory at least) they know exactly what benefits they will become entitled to, as does the employer, but the disadvantage to employers is they do not know for certain what the benefit promises will actually cost them.

With defined-contribution schemes the uncertainties are transferred to the employees and the certainties lie with the employers. Employers limit their promises solely to the amount of money they will invest for their employees' pensions and that money is built up in a fund which is used to purchase benefits on death, retirement or leaving service. The employees in these schemes know what is being put aside for them, but they do not know for certain how much it will provide in terms of benefits. The risks associated with investment returns and with annuity purchase have been transferred to the employees. It is on this basic structure of both benefit and contribution limitations, combined with the defined-benefit and the various defined-contribution alternatives that the complexities applying to occupational schemes are based.

For occupational pension schemes it is easy to see what has caused complexity to build up:

- piecemeal legislation that has concentrated on specific problems in isolation. (The result has too often been further problems in different areas; a bit like trying to sort out one face of a Rubik's Cube without worrying about what happens to the other faces that have previously been worked on).

- the mixture of common law, trust law and detailed primary legislation, backed up by a plethora of regulations and amending regulations. On top of this are overlaid the numerous discretionary practices of the Inland Revenue to deal with specific cases.

That is not to say that this has necessarily been a bad thing or something which could have been avoided. That the legislation has spawned a strong pensions savings culture in the UK there is no doubt. It is difficult to see how the sum total could have been built up in anything other than the piecemeal fashion that it was. Looking at each piece of legislation in isolation, no one would disagree with the good reasons and 
intentions that were behind them nor the rationale behind the many decisions to deal with the various problems and issues that have arisen over the last 45 years since the modern pensions era began in 1956. However, any reasonable assessment today of the edifice in its entirety would, I think, conclude that the very complexity that has arisen as a result has itself become the main impediment to the continuing effectiveness of the system as a whole.

Today there are four different tax regimes that can apply to occupational scheme members (for the last 12 years there were merely three, and 15 years ago there was only one) and all such employees are classified by the Inland Revenue accordingly. People in occupational pension schemes are either Class A members, Class B members or Class $\mathrm{C}$ members, or they are covered by the provisions of the New Defined-Contribution regime. In practice this means that employers offering occupational scheme membership to their employees need to operate schemes that allow for, at least, all the first three classes of member and their different defined-benefit limits. This applies to all defined-benefit occupational schemes including those that are defined-contribution occupational schemes that are limited by the defined-benefit limits. It does not, however, apply to occupational defined-contribution schemes that operate under the New Defined-Contribution tax regime established in April 2001, where the existing Personal Pension contribution limits apply, even though the scheme is operated on an occupational scheme basis. Indeed, it may even have been a scheme or part of a scheme, that has switched from the defined-benefit limited

defined-contribution regime to the New Defined-Contribution regime, an option open to the trustees of such schemes since April 2001.

This situation, which is not unusual, together with the existence of the similar-looking, but entirely different, groupings of personal pensions (known as GPPs) which also appear to be occupational pension schemes but are not (not to mention the new group versions of Stakeholder pension schemes which are sometimes classed as occupational Chapter 1 schemes and sometimes not) make it very difficult for members of employer-sponsored schemes these days to answer even simple questions like 'Are you a member of an occupational pension scheme provided by your employer?' Most employers probably would not know the difference if their employees asked them either. This is not a trivial point. It is a very important question which is posed to anybody thinking of paying into an individual pension top-up to add to their employer's scheme benefits.

Unfortunately, such inconsistencies serve only to confound further and frustrate those trying to put a little extra money aside for their retirement.

However, all of this is made doubly difficult, and completely surpassed in terms of pointless complexity, by the fact that individuals who are classified as Classes A, B and C by the Inland Revenue also have various choices they can make, including being able to switch classification.

People who joined an occupational pension scheme before 17th March, 1987 are Class $\mathrm{C}$ members; people who joined occupational pension schemes between 17th March, 1987 and 31st May, 1989 are Class B members; and people who have joined occupational pension schemes after 1st June, 1989 are Class A members. However, there are exceptions and it is possible for people joining occupational pension schemes after 1 st 
June, 1989 to be classed as Class B, or even Class $\mathrm{C}$ members.

Also, a Class $\mathrm{C}$ member has the right to elect to be treated as a Class B member and, where a particular occupational scheme's rules have been suitably amended to permit it, Class B or Class $\mathrm{C}$ members of that scheme can elect to be treated as though they are Class A members.

Obviously there are advantages to be gained sometimes by making such elections if you are able to, as well as disadvantages in not making potentially advantageous elections which, although available, may not have been properly appreciated (or even known about) by any given individual at any time. There is also the danger that people could elect to change tax regimes and become worse off simply because they did not understand the implications of what they were doing.

From an employer's point of view things can be doubly difficult. While a full understanding of benefit calculations is obviously important to employers who offer their staff a defined-benefit scheme, it is important to note that even where employers offer the simpler concept of defined-contribution schemes the defined-benefit rules still apply. So, if an employee is a member of a defined-benefit limited, defined-contribution scheme (otherwise known as a Chapter 1 money-purchase scheme) then checks have to be made to ensure that the benefits being provided by the accumulated fund will not exceed the maximum permissible benefits that would be allowed for someone of that classification had they been a member of a defined-benefit scheme. So there is no escape from the complications and costs there for employers.

At this point it will be necessary, and helpful to explain the way Chapter I and Chapter IV schemes operate, and to explain exactly what they are. It will make it simpler to understand how and why our occupational schemes are configured as they are and how they relate to the enormously important individual pension regimes, which include Personal Pensions, Retirement Annuity Contracts and Stakeholder Pensions, subjects I have hardly touched on so far in this paper.

A Chapter I scheme is what we think of as a 'traditional' occupational scheme and can be either defined-benefit or defined-contribution, as has been discussed earlier in this paper. It is called a Chapter I scheme because it is approved for tax purposes under Chapter I of Part XIV of the Income and Corporation Taxes Act (ICTA) 1988.

A Chapter IV scheme, on the other hand, is a Personal Pension scheme approved under Chapter IV of Part XIV of ICTA 1988. Prior to 6th April, 2001 only Personal Pensions were approved under this tax regime. That also included groupings of Personal Pensions (GPPs), which look like occupational schemes, but are not, and Appropriate Personal Pension Schemes (APPS) which can be used by individuals to hold rebates of monies from the state second-tier pension scheme which is currently known as Serps.

A new tax regime, the New Defined Contribution tax regime, was introduced on 6th April, 2001. This was achieved by a change in tax approval under Chapter IV, Part XIV of ICTA 1988 which included Stakeholder Pension schemes and allowed occupational defined-contribution schemes to seek approval under Chapter IV. This change has been permitted following regulations under the Welfare Reform and Pensions Act 1999 which also introduced Stakeholder Pensions. There was also a corresponding change to Chapter I approval allowing existing Chapter I 
approved schemes to switch to the Chapter IV regime, as long as certain criteria are satisfied in advance. For tax approval purposes the Inland Revenue refer to all of the arrangements under the New Defined Contribution regime as Personal Pensions, even though they may in fact be occupational schemes which adopt the new regime (either Stakeholder or Non-Stakeholder occupational schemes).

The distinguishing feature of a Chapter IV Occupational Pension Scheme is that it is covered by some legislation which affects Chapter I schemes and other legislation which affects Chapter IV schemes. What this means in broad terms is that where an Occupational Pension Scheme elects to be part of the New Defined Contribution regime, the switch will mean that the members will look like they have got Personal Pensions (which is not quite the case), but the scheme will remain as an Occupational Pension Scheme as defined by the Pension Schemes Act 1993, even though many of the rules that apply to occupational pension schemes will not apply to it. This may lead to some confusion, for example when people leave such schemes where they will be treated as though they are leavers from an Occupational Pension scheme in terms of disclosure of information purposes, but as leavers from a Personal Pension scheme for the purposes of deferred benefits.

However, as the change of approval relates only to a change in Inland Revenue regulations, Department of Social Security regulations are unchanged. Even though the National Insurance Contributions Office is now a division of the Inland Revenue, the underpinning regulations regarding National Insurance rebates (for those contracting out of the Serps scheme into a Personal Pension or an Occupational
Pension scheme) take the form of DSS regulations. Therefore, a defined-contribution Chapter I scheme switching to the New Defined Contribution regime will continue to receive rebates from the State second-tier scheme at the level that applies to Occupational schemes, rather than at the higher Appropriate Personal Pension rate that applies to Personal Pensions. This is less advantageous to the people concerned and quite difficult for them to understand, as from where they are standing it will look very much like they are in a Personal Pension scheme. So two people who had identical personal circumstances and State pension entitlements could elect to leave the Serps scheme and would be given a rebate of their National Insurance contributions in lieu of the benefits being surrendered, but would get different amounts of rebates for surrendering the same benefit.

This leads to a point where a brief summary of the many individual pension regimes that currently co-exist in th UK, and of the ways in which they interact with each other and all of the various occupational regimes, would be useful.

The six regimes comprise: Retirement Annuity Policies, two types of Personal Pension Schemes, Additional Voluntary Contribution schemes, Free-Standing Additional Voluntary Contribution Schemes and Stakeholder Pensions. There are sub-sets of these too, I know, but just describing what these are will probably do for now.

The important thing to bear in mind is that all of these different tax regimes provide for individual pension products that are defined-contribution based, although some of them are subject to the occupational defined-benefit limits. They are all contribution-limited, but the contribution limits and benefit limits are different for each one. The other thing 
to bear in mind is that most people cannot tell the difference between any of them and think they are all Personal Pensions anyway.

Retirement annuity policies were introduced by the 1956 Act and were still available until 1988 and anybody who has one can not only keep it, but can continue contributing to it; and around three-quarters of a million people are doing just that today. These are referred to by many as Section 226 plans and by many others as Personal Pensions; in fact, many of them were marketed as personal pension plans in the days before Personal Pensions existed. This obviously leads to much confusion and always has done.

Retirement Annuity Policies have different contribution limits to both types of Personal Pension and Stakeholder Pensions (and Additional Voluntary Contribution schemes and Free-Standing Additional Voluntary Contribution Schemes for that matter) and produce different benefits on retirement. They are quite inferior to Personal Pensions and Stakeholder Pensions in that people cannot contribute as much to them; the permitted retirement ages are restricted; employers can not contribute to them; and they may not be used to contract out of the State second-tier pension scheme. They can, however, produce more tax-free cash at retirement than Personal Pensions or Stakeholder Pensions can, depending on what interest rates happen to be at the time that people retire. For this reason people who have these contracts would be foolish to close them down. They can, however, also produce less tax-free cash for the same reason. This should not be a problem, though, because it is possible to switch from a Retirement Annuity Policy to a Personal Pension or a Stakeholder Pension at any time. However, as it is not permissible to switch back again it is inadvisable to do so other than at the actual point of retirement when the level of interest rates is known.

Retirement Annuity Policies have always been able to be held concurrently with Personal Pensions, but not with Chapter I Occupational Pensions, unless a person has two sources of income. Even though they are defined-contribution arrangements they (along with Additional Voluntary Contribution Schemes and Free-Standing Additional Voluntary Contribution Schemes) have been excluded from the New Defined Contribution tax regime. However, although they are not part of this concurrent regime, rule changes have been made to allow them to be held concurrently with other New Defined Contribution approved pension arrangements anyway. Similar allowance has not been made for Additional Voluntary and Free-Standing Additional Voluntary Contribution Schemes which can not be held concurrently with Chapter IV approved pensions unless they are held by someone who is subject to the partial-concurrency rules, when they can be.

Personal Pensions, which were modelled on Retirement Annuity Policies were introduced in 1988 and were substantially amended in 1989. This means that the Personal Pensions started before July 1989 have better benefits than those started after that date. One of the principal differences being that more tax-free cash can be taken sometimes by some people (it depends really on whether the Personal Pension has taken on the responsibility of Protected Rights or not).

Personal Pensions (both types) are contribution-limited defined-contribution schemes like all the other individual pensions arrangements, again with their own exclusive levels of allowable contributions and benefit restrictions. 
People who are in Chapter I occupational schemes who want to save more for their retirement can do so with Additional Voluntary Contributions too. Indeed, it is against the law for employers not to offer Additional Voluntary Contribution facilities if they run a Chapter I occupational scheme. (Perversely, it would be against the law to do so if they run a Chapter IV Occupational scheme, so it is important that employers understand the difference.)

Additional Voluntary Contributions and Free-Standing Additional Voluntary Contribution Schemes are very much like Personal Pensions in that they are contribution-limited, but they are unlike Personal Pensions and Stakeholder Pensions in that they do not provide a tax-free cash sum at retirement unless payment commenced before 8th April, 1987. (Although extra tax-free cash can be generated using the combination of the two point two five times rule and a switch to the post-1989 tax regime).

Additional Voluntary Contributions and Free-Standing Additional Voluntary Contribution Schemes are also subject to the overall benefit limits of the Defined-Benefit rules described earlier, which Personal Pensions, Stakeholder Pensions and Retirement Annuity Policies are not.

Stakeholder Pensions, introduced in April 2001, are in fact post-1989 Personal Pensions with some restrictions, particularly in the way charges can be levied by pension providers. In all other respects they are the same as, and indeed are, Personal Pensions. All the existing rules applying to Personal Pensions therefore apply to Stakeholder Pensions as well.

\section{Conclusion}

As the foregoing makes very clear, changes to pension regimes has been a consistent feature of most administrations' legislative programmes through the last century. It is also patently clear that, despite some of the very best schemes in Western Europe, if not the world, our pension system does not achieve what it should: offering true choice and opportunity for all people. The sheer illogicality of the changes to both occupational and personal pension schemes is beyond belief. If only it were the pensions industry to blame for such complexity and, at times, obfuscation; but we are not (though we have been complicit), and the responsibility - and perhaps the solution - lies with governments and administrators.

Given the platform of savings current schemes support, and given the intent behind the introduction of stakeholder to widen the scope of participation in saving, is it not sensible to evaluate now ways in which current schemes can be improved without recourse to measures such as compulsion? Equally, given the standing of the UK's schemes within Western democracies, is it also not sensible to reform this system to claim it as the best model within the EU should politicians be so determined as to introduce community-wide plans that could undermine the UK's system? Finally, and something which is selfevident to most of us interested in this subject, it is human nature to seek advice and information on issues we do not properly understand. So if it is a political imperative to widen participation among the less well-off, increase uptake, and thus reduce the pressure on State finances, then surely it must be possible for those that want to implement lasting improvements to society to bring together all sides to deliver such change?

It is a welcome development to see that the current government has announced its intention to simplify the pensions regime. Indeed, two separate 
reviews have been established by different government departments to begin this process; the Pickering Review which is sponsored by the Department of Work and Pensions, and the Sandler Review sponsored by the Treasury. These are both set to make recommendations later this year, but for those of us judging the results of their work it is difficult to know which benchmarks we can look to if we are to comment on simplification. Pensions seems almost too broad and multi-faceted a subject to allow simple judgments on simplification itself. It is this issue that has been exercising my mind and those of my colleagues lately.

We now believe we have established a framework against which any plans for pension simplification can be judged. In our considered view, there are three key principles that any proposals will need to incorporate if simplification is to be claimed. These are; Transition, Separation, and True Concurrency. Our detailed thinking and rationale for our conclusions need a paper longer than this to explain, but it may be worthwhile here to outline what we mean by Transition, Separation and True Concurrency so that readers can understand their significance in the context of the foregoing description of the current complexities of the UK pensions system.

Of the three principles, Transition is perhaps the most important. It has been a hallmark of all previous pensions legislation in the UK, including that heralded as 'pension reform', that no retrospective changes have ever been made. The resulting 'layers of simplification' therefore have simply added to the, and become yet other, layers of complexity within the system. The principle of Transition would require that new, simpler pensions regimes would be established to replace the existing regimes and that all individuals and companies operating existing pension schemes would be required to close them and move to the new, simpler basis.

Governments have shied away from this radical approach before because of the fear that some would lose valuable rights attached to previous legislation. It is a sound fear, but one that needs turning on its head; a new, simpler pensions regime must allow for all of the advantageous rights from past legislation to apply not just to the lucky few, but to all pension savers.

This may be a difficult area for the government, but it should not be. Any genuine claim for simplification can only be made if Transition is a requirement. Anything else would merely be the establishment of yet another layer of complexity or, worse still, just a cosmetic exercise in tinkering at the edges of the many problems inherent in the current fragmented pensions system.

The second principle, Separation, builds on the first and recognises the fact that occupational pensions, state pensions and individual pensions are distinct from one another and should be treated as such by legislation. In plain English, it is our belief that occupational pension schemes should not be allowed to interact with the state schemes (ie, contract-out); that occupational pension schemes should not be able to include contributions from individuals; and that where people do elect to contract-out of the state schemes (on an individual basis only), that the State should give up any right to prescribe how such rebate monies are used by individuals to purchase retirement benefits.

Transition would also require that Separation is applied retrospectively. Again, in plain English, what this would mean would be that all contributions made by individuals towards their own 
pensions would be covered by a new simpler individual pensions regime, irrespective of whether such contributions in the past were made to state pension schemes, occupational pension schemes or individual pension schemes. It would also mean that occupational pension schemes would be just that, pensions provided for employees by their employers, again covered by the terms of a new simple occupational pensions regime incorporating all the best features of existing arrangements and making them available to all. The state pension schemes, other than where individuals buy themselves out by accepting full National Insurance rebates, would continue to accrue separate and additional benefits to those being produced by corporate or individual arrangements.

That all three regimes, state, corporate and individual would co-exist with no reference to each other, and no limitations imposed on any one by any other, is the third principle we recommend: True Concurrency. What an individual chooses to do to provide for himself or herself in retirement should not be subject to limitation because of what his or her various employers choose to provide, or what the State may or may not choose to provide, for them during their working lives.

Separation means that True Concurrency will exist. True Concurrency means that pension products geared to genuine long-term savings habits can prosper in the marketplace. Transition means that existing complexities and conflicts will cease to be a problem to those trying to save and that onerous costs of distribution and compliance will be substantially reduced. In our view, any attempt at simplifying the UK pensions system that does not incorporate these three principles will not be able to be described as being radical.

Steve Bee Head of Pensions Strategy Scottish Life 